\title{
Economic assessment of changes to an existing medication therapy management program of a large regional health plan
}

\author{
Samuel K Peasah, PhD, MBA, RPh; Tracy Hammonds, PhD; Yushu Liu, PhD; Vanessa Campbell, PharmD; \\ Chronis Manolis, RPh; and Chester B Good, MD, MPH
}

\section{What is already known about this subject}

- There are minimum requirements for eligibility to the medication therapy management (MTM) program for Medicare Part $D$ beneficiaries, but it is not mandated for other health plan types such as Medicaid and commercial.

- Several studies with different target populations have shown clinical and economic benefits of the program.

- Flexibility, variability, and expanding eligibility is inherent with the program, making continuous evaluation of these benefits necessary.

\section{What this study adds}

- This study used a robust difference-indifference model that compared the intervention group with a propensity score-matched historical control group to estimate the effect of expanding the eligibility criteria and delivery intensity of an existing MTM program on total cost of care, utilization of health care resources, medication adherence, and return on investment (ROI).

- There were reductions in unplanned care, total cost of care, and increases in medication adherence in 4 therapeutic classes: anticoagulants, cardiac medications, statins, and antidepressants.

- There was an ROI of $\$ 18.50$ per each dollar spent and increased medication adherence across several chronic conditions especially among Medicaid recipients.

evolved with time to more streamlined and robust interventions, necessitating ongoing evaluation of the effect on clinical and economic outcomes.

OBJECTIVE: To assess the effect of changes to an existing MTM program on cost of care, utilization, and medication adherence.

METHODS: UPMC Health Plan made changes to an existing MTM program by expanding eligibility (customized by the type of health plan), intervention types, pharmacist involvement, and patient followup contacts. After matching our intervention cohort (identified January 2017-June 2018)

\begin{abstract}
Author affiliations
Samuel K Peasah, PhD, MBA, RPh, and Chester B Good, MD, MPH, Value-Based Pharmacy Initiatives, Center for High Value HealthCare, UPMC Health Plan, Pittsburgh, PA. Tracy Hammonds, PhD, and Yushu Liu, $\mathrm{PhD}$, Health Economics, UPMC Health Plan, Pittsburgh, PA. Vanessa Campbell, PharmD, and Chronis Manolis, RPh, Pharmacy Services, UPMC Health Plan, Pittsburgh, PA.
\end{abstract}

\section{AUTHOR CORRESPONDENCE:}

Samuel K Peasah, 412.454.5129;

Peasahsk@upmc.edu

J Manag Care Spec Pharm. 2021;27(2):147-56

Copyright $\odot 2021$, Academy of Managed Care Pharmacy. All rights reserved.

with the pre-2016 MTM historical controls (patients identified January 2014-June 2015 who would have been eligible if we used the intervention cohort eligibility criteria), we estimated that the effect of the program changes with a difference-in-difference model (preintervention [2014-2016] and postintervention [2017-2019]). Outcomes of interest included cost (total cost of care including medical, pharmacy, and unplanned care [i.e., unscheduled health care use such as emergency department visits] in 2017 U.S. dollars); utilization; medication adherence (proportion of days covered); and return on 
investment (ROI). Target population included continuously enrolled patients aged $\geq 21$ years in the commercial, Medicare, and Medicaid health plans.

RESULTS: Total propensity score-matched members was $10,747,55 \%$ of which were in the historic control group. The average (SD) ages after matching the groups were similar (historical control group: 57.08 years [14.23], intervention group: 56.79 years [14.21]) and the majority was female (57\%). Comorbidities identified most for patients included hypertension (77\%), dyslipidemia (70\%), and diabetes (52\%). Forty-one percent were in the commercial, $37 \%$ in the Medicaid, and $23 \%$ in the Medicare health plans. Proportion of care activities undertaken in the intervention period compared with the control period were significantly different: "sent letter to physician" (67\% vs. 87\%), "sent letter to member" ( $15 \%$ vs. $0 \%)$, "pharmacist phone call to physician" ( $15 \%$ vs. $0.1 \%)$, and "pharmacist phone call to member" (13\% vs. $7 \%)$. There were statistically significant reductions in unplanned care across all health plans especially in the Medicare population, in total cost of care, and increases in medication adherence in 4 therapeutic classes: anticoagulants $(O R=1.25, P=0.005)$, cardiac medications $(O R=1.20$, $P<0.001)$, statins $(O R=1.21, P<0.001)$, and antidepressants $(O R=1.15$, $P<0.001)$. There was a positive ROI of $\$ 18.50$ per dollar spent, which equated to a cumulative net savings of $\$ 11$ million over 24 months.

CONCLUSIONS: In a large health plan, expanding MTM eligibility, intensifying patient follow-up contact and pharmacist involvement, and improving provider awareness had favorable clinical and economic benefits.

The goals of medication therapy management (MTM)medication optimization, adverse drug event reduction, and patient empowerment-align with the goals of pharmaceutical care, which have redefined pharmacy practice since it was included in the Medicare Modernization Act of $2003 .{ }^{1}$ Congress believed these goals were necessary for optimal care for Medicare beneficiaries, and thus the Centers for Medicare \& Medicaid Services (CMS) mandated MTM services for specific Medicare beneficiaries as part of contracts with Medicare Advantage and stand-alone Prescription Drug Plan providers. ${ }^{2,3}$ Eligibility of patients for MTM services is set yearly by CMS, based on number and type of chronic conditions, the number of prescription drugs filled, and the projected annual cost of prescription drugs. ${ }^{3}$ For example, in 2019, the target population were patients with all of the following: (a) having multiple chronic diseases (3 of 9 core chronic conditions required as the minimum for eligibility-the 9 core chronic conditions include Alzheimer disease, chronic heart failure, hypertension, and diabetes); (b) taking multiple Part D drugs (a minimum of 8 is required for eligibility); and (c) likelihood that the projected annual cost of Part D drugs for an individual patient will exceed the minimum threshold of $\$ 4,044 .^{3,4}$

The general consensus in the research community and with policymakers is that MTM outcomes have been beneficial but with wide variations of results. ${ }^{5-20}$ These outcomes have included clinical (e.g., resolution of medication-related problems and hospital readmissions); economic (e.g., return on investment [ROI]); and humanistic (e.g., patients' satisfaction with the service), but some of these outcomes were proxy or surrogate measures, such as high blood pressure reduction. MTM, originally mandated for Medicare beneficiaries, has since been adopted or recommended by third-party payers that include Medicaid and commercial plans.

The MTM concept has been part of the practice of pharmacy since the 1990s. Although CMS, in conjunction with pharmacy organizations such as the American Pharmaceutical Association, has defined the 5 core elements of MTM, the scope and intensity of MTM interventions and type of practitioners administering MTM differ. The core elements include medication therapy review (often a comprehensive medication review [CMR] but could be a targeted medication review [TMR]), a personal medication record, a medication-related action plan, intervention or referral, and documentation and follow-up. ${ }^{5}$ MTM services can be delivered face-to-face, by telephone, or by mailings; in different settings (e.g., community pharmacies, outpatient settings, MTM vendors, pharmacy benefit managers, and health plans); and by different health care providers (mainly pharmacists but could include nurses and case managers), which potentially explains the differences in outcomes and scope of practice..$^{5-20}$

The type and intensity of MTM services delivered have evolved with time from just patient education to more streamlined and robust interventions, necessitating ongoing evaluation of the effect on clinical and economic outcomes. There are also minimum requirements for eligibility in the Medicare program and no mandated requirements for the other non-Medicare health plans, such as commercial plans and Medicaid.

The objective of this study was to assess the effect of expanded patient eligibility (customized by the type of health plan) and intensity changes of an existing MTM program on clinical and economic outcomes across an integrated health delivery system. In 2019, 27\% sponsors expanded eligibility beyond the CMS minimum requirement to offer MTM services to more beneficiaries. ${ }^{4}$ 


\section{TABLE 1 MTM Intervention Targets, Description of Targets, and Interventions Provided}

\begin{tabular}{|c|c|c|c|}
\hline Intervention Target & Description & Intervention & Historical Control \\
\hline $\begin{array}{l}\text { Therapeutic } \\
\text { duplication }\end{array}$ & $\begin{array}{l}\text { Targets commonly used medication classes in which } \\
\text { patient may be taking } 2 \text { medications that are in the } \\
\text { same family, leading to significant side effects }\end{array}$ & $\begin{array}{l}\text { Combination of calls (by pharmacist) and } \\
\text { letters to providers }\end{array}$ & Letters to providers \\
\hline Adherence & $\begin{array}{l}\text { Targeting the classes of medications that may lead to } \\
\text { inadequate disease control if not taken consistently }\end{array}$ & $\begin{array}{l}\text { Combination of letters to patients and } \\
\text { calls from nurses and pharmacists }\end{array}$ & $\begin{array}{l}\text { Calls to patients } \\
\text { from nurses }\end{array}$ \\
\hline Overuse & $\begin{array}{l}\text { Targets classes of drugs that should be used sparingly } \\
\text { for control of symptoms and more frequent use may } \\
\text { indicate inadequate control }\end{array}$ & Pharmacist calls to patients & $\begin{array}{l}\text { Calls to patients } \\
\text { from nurses }\end{array}$ \\
\hline $\begin{array}{l}\text { High-risk } \\
\text { medication }\end{array}$ & $\begin{array}{l}\text { Targets high-risk medications in members aged } 65 \\
\text { years and older, regardless of quantity or duration } \\
\text { filled }\end{array}$ & Letters to providers & Letters to providers \\
\hline $\begin{array}{l}\text { Drug-drug } \\
\text { interactions }\end{array}$ & $\begin{array}{l}\text { Targets contraindicated drug combinations (based off } \\
\text { First DataBank drug tables) }\end{array}$ & Letters to providers & Letters to providers \\
\hline Lab monitoring & $\begin{array}{l}\text { Targets frequently used medications that have } \\
\text { yearly lab monitoring required for continued use as } \\
\text { described in package insert }\end{array}$ & Letters to providers & Letters to providers \\
\hline $\begin{array}{l}\text { Drug-disease } \\
\text { contradictions }\end{array}$ & $\begin{array}{l}\text { Targets medications that are generally regarded as } \\
\text { contraindicated with disease state listed }\end{array}$ & $\begin{array}{l}\text { Pharmacist calls to provider for high risk } \\
\text { of hospitalization (CHF, thromboembolism, } \\
\text { MI/stroke risk), letters to provider on all } \\
\text { other classes }\end{array}$ & Letters to providers \\
\hline Therapeutic gaps & $\begin{array}{l}\text { Targets gap in therapy of specific condition, most } \\
\text { based on HEDIS measures }\end{array}$ & $\begin{array}{l}\text { Combination of letters and pharmacist } \\
\text { calls to providers }\end{array}$ & Letters to providers \\
\hline High dose & $\begin{array}{l}\text { Targets medications with newly changed maximum } \\
\text { daily dose (per FDA alerts) and other medication } \\
\text { classes }\end{array}$ & $\begin{array}{l}\text { Combination of letters and pharmacist } \\
\text { calls to providers }\end{array}$ & $\begin{array}{l}\text { Did not exist before } \\
2016\end{array}$ \\
\hline
\end{tabular}

$\mathrm{CHF}=$ chronic heart failure; FDA =U.S. Food and Drug Administration; FDB=First DataBank; HEDIS=Healthcare Effectiveness Data and Information Set;

$\mathrm{MI}=$ myocardial infarction; $M$ TM= medication therapy management.

\section{Methods}

\section{THE MTM PROGRAM BEFORE AND AFTER 2016}

UPMC Health Plan, which is part of an integrated health delivery and financing system, is a regional health plan based in western Pennsylvania, with more than 3.8 million members, providing commercial plans (including health insurance exchange plans for individuals), Medicare, Medicaid, and the Children's Health Insurance Program. UPMC uses a stratification algorithm consisting of medical, pharmacy, and laboratory claims to identify patients eligible for its MTM program. When members meet enrollment criteria they are contacted. TMRs occur simultaneously with the offer to enroll into the MTM program unless the patient opts out. As a result of the TMR, 9 potential intervention targets may be identified, including issues of medication compliance, high-risk medications, drug-drug interactions, and high-dose medications (Table 1). Once potential intervention targets are identified, patient cases are reviewed and acted on. Member outreach efforts through TMRs could occur anywhere from every 60 days to 6 months, depending on the issue identified and the line of business. TMRs occur across all lines of business, but in addition, Medicare and Special Needs Plan beneficiaries receive CMRs.

The MTM program for Medicare before 2016 met CMS criteria. After 2016, changes were made to the program that included additional disease states added to eligibility criteria, which increased the number of Medicare patients included in the program, and the MTM interventions were made more robust. Before 2016, the health plan MTM criteria for Medicaid and commercial eligibility were similar to CMS disease states criteria for Medicare (with some modifications based on the algorithm); however, for the minimum covered chronic medication criteria, UPMC required more than 8 medications (CMS requires a minimum of 8 Part D medications for Medicare beneficiaries), ${ }^{4}$ and no requirement was set for the drug spend criteria.

In 2016, extensive changes were made to the Medicaid and commercial health plans. These changes focused on 2 main areas: further expanding criteria for program eligibility and modifying the deployment of interventions. 


\section{FIGURE 1 Consort Chart Showing MTM Members Who Were Eligible for Matching}

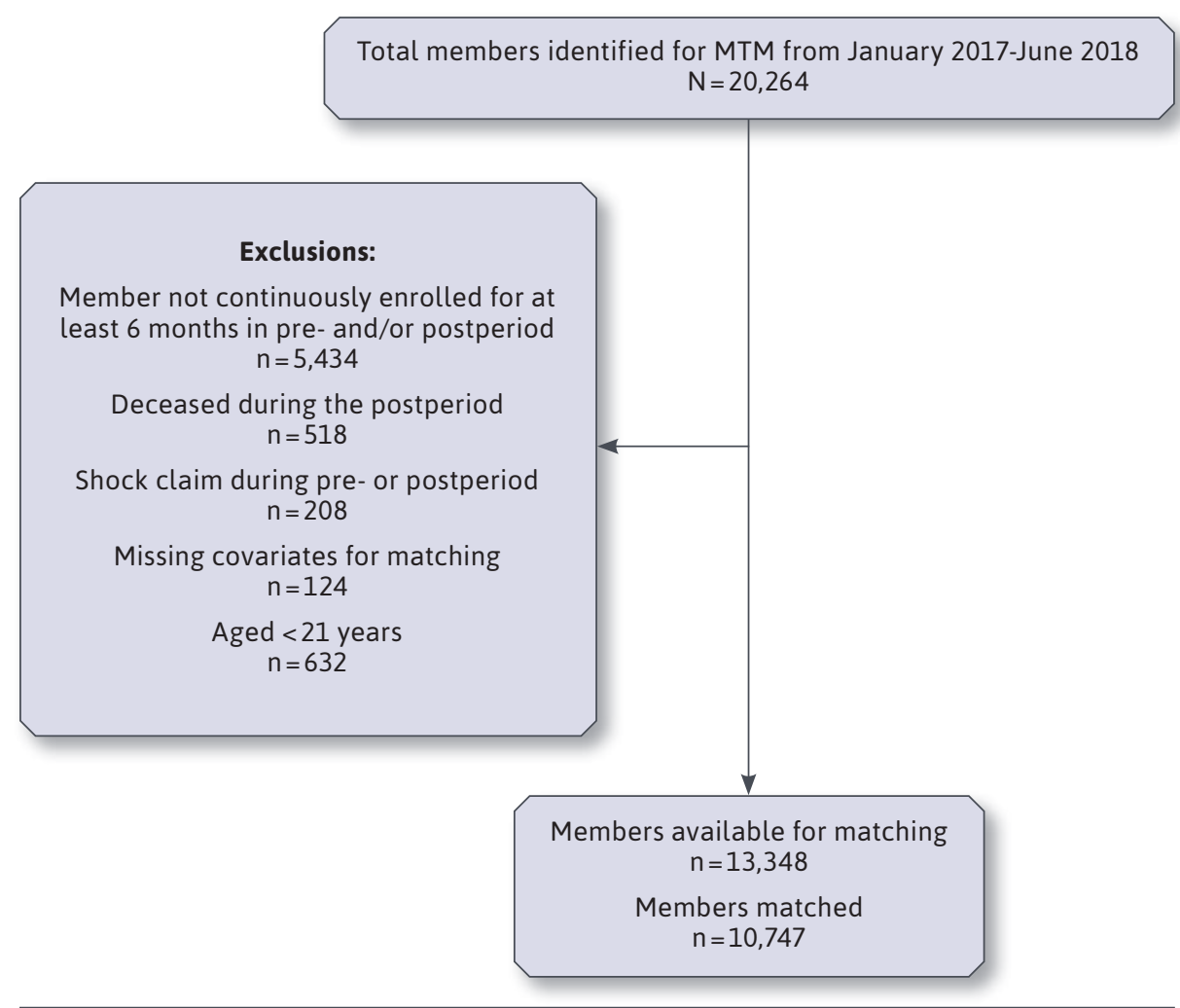

MTM = medication therapy management.

Specifically for UPMC, MTM eligibility criteria incorporated additional chronic disease states (e.g., multiple sclerosis and chronic obstructive pulmonary disease [COPD]) and lowered the required number of the chronic diseases. The requirement for number of chronic medications remained above 8. Additional changes after 2016 (for all lines of business) included adding cardiac disease states, inflammatory conditions, and behavioral health disorders. These modifications allowed more members to be added to the MTM program.

Regarding interventions for Medicare, Medicaid, and commercial plans before 2016, the primary communication with providers was via letter. To be more interactive, UPMC shifted to outreach calls to coordinate directly with provider practices and used highly engaged pharmacists to perform outreach to providers and members in order to make clinical medication recommendations. Member letters were also used in the post-2019 intervention period to provide reinforcement on medication-related topics to enhance understanding. In summary, the MTM program before 2016 was expanded by relaxing the eligibility requirements, allowing more patients to qualify. In addition, pharmacist involvement was enhanced, and telephone calls replaced mailed materials to patients and providers. These intervention changes from 2016 to current practice are summarized in Table 1.

\section{STUDY DESIGN}

This was a retrospective, observational comparison analysis of members enrolled in the MTM program between January 2017 and June 2018 (intervention group) versus a propensity-matched historical comparator group from January 2014 to June 2015 (control group) to determine how the expanded MTM interventions affected cost of care, utilization, and medication adherence across Medicare, Medicaid, and commercial health plans.

To be included in the analysis, members were required to be aged $\geq 21$ years and have 6 months of continuous membership before and after program enrollment to establish baseline and follow-up cost of care and utilization. Members with a shock claim (UPMC reinsurance policy across all lines of business, defined as $>\$ 75,000$ per individual claim) during the study period were removed from the analysis (Figure 1).

Patients in the historical comparator group identified between January 2014 and June 2015 were followed for at least 6 months but not more than 12 months to assess patient health resource utilization and cost. Similarly, patients in the intervention group identified between January 2017 to June 2018 were followed for at least 6 months and up to 12 months. The eligibility requirements were based on number and type of chronic conditions, type of mental health issues, number of different pharmaceutical prescriptions filled, and pharmaceutical spend. In addition, identified historical comparators were 1:1 propensity matched to the intervention group by age, gender, insurance type, socioeconomic status (area deprivation index), baseline cost, and utilization (Table 2). 


\section{TABLE 2 Descriptive Characteristics of Members Enrolled in MTM Program Versus Historical Comparators Before and After 1:1 Propensity Matching}

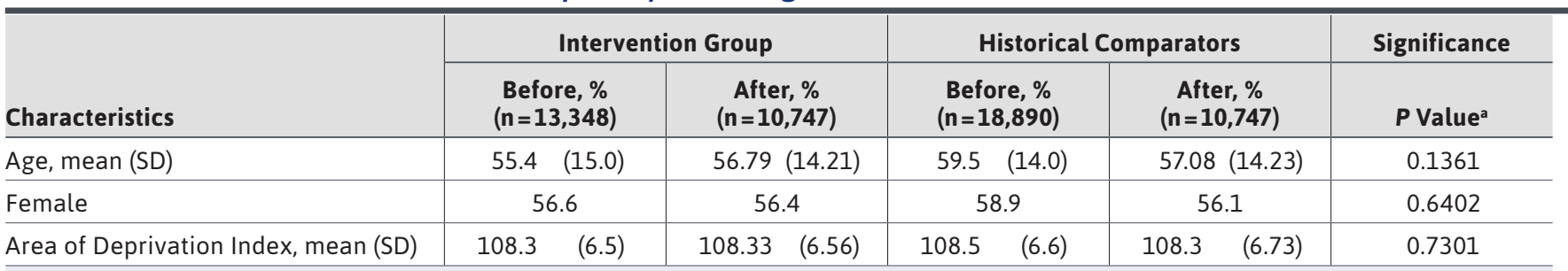

Insurance plan

\begin{tabular}{l|l|l|l|l|l|}
\hline Medicare & 23.1 & 25.14 & 36.3 & 25.14 \\
\hline Medicaid & 39.9 & 35.54 & 30.9 & 35.54 \\
\hline Commercial & 37.0 & 39.31 & 32.9 & 39.31 & 1.000 \\
\hline
\end{tabular}

\section{Age-adjusted $\mathrm{CCl}$}

\begin{tabular}{|c|c|c|c|c|c|}
\hline $0-1$ & 23.1 & 17.26 & 12.1 & 17.4 & \multirow{4}{*}{0.9906} \\
\hline $2-3$ & 25.2 & 26.38 & 23.2 & 26.43 & \\
\hline $4-5$ & 20.5 & 22.58 & 23.4 & 22.45 & \\
\hline $6+$ & 31.2 & 33.78 & 41.3 & 33.72 & \\
\hline Asthma & 20.5 & 21.66 & 23.8 & 21.25 & 0.4647 \\
\hline CAD & 25.7 & 29.08 & 37.7 & 28.97 & 0.8569 \\
\hline COPD & 20.8 & 22.69 & 27.7 & 22.1 & 0.3026 \\
\hline Cancer & 9.7 & 10.41 & 11.9 & 10.47 & 0.8935 \\
\hline Hyperlipidemia & 64.2 & 70.25 & 76.5 & 70.20 & 0.9287 \\
\hline Hypertension & 71.7 & 77.44 & 83.4 & 77.08 & 0.5256 \\
\hline Diabetes mellitus & 46.2 & 52.61 & 60.6 & 52.04 & 0.4048 \\
\hline Behavioral health condition & 54.4 & 46.41 & 40.4 & 46.07 & 0.6127 \\
\hline Shared savings group & 39.8 & 39.10 & 35.4 & 39.30 & 0.7374 \\
\hline
\end{tabular}

${ }^{a} P$ values displayed are for after matching. $P$ values before matching were all statistically significant.

bShared savings: incentive payments for networked physician groups for meeting metrics similar to the Medicare Shared Savings Program.

$\mathrm{CCl}=$ Charlson Comorbidity Index; $\mathrm{CAD}=$ coronary artery disease; $\mathrm{COPD}=$ chronic obstructive pulmonary disease.

\section{STATISTICAL ANALYSIS}

Descriptive analysis was conducted and included means and SDs for continuous variables and percentages and frequency for categorical variables. Chi-square analysis or Fishers exact testing (cell size $\leq 5$ ) was conducted to determine differences between baseline risk categories for categorical variables.

For each of the medication classes analyzed, medication adherence was determined by calculating the proportion of days covered (PDC), which is the number of days a member has a prescription within a given therapeutic drug class on hand based on the prescription fill date and days supplied divided by the number of days in the treatment period (covered days). If multiple, different prescriptions within a given therapeutic class were filled on the same day or overlapped in days, the number of days supplied was counted once (e.g., 30-day supply of drug A and drug B filled 5-days apart, then days on hand was 35 days). If the multiple prescriptions of the same drug were filled on the same day or overlapped in days, then the number of days supplied were applied sequentially (e.g., three 30-day supplies of drug A were filled on the same day, then days on hand was 90 days).

A difference-in-difference approach was used to calculate treatment effect (i.e., effect attributable to the MTM program) for the intervention versus the comparison group. To account for right skewness, a generalized linear model (GLM) with a gamma distribution, and log link function was used to fit the model for cost. A GLM with a Poisson distribution and log link function was used to analyze utilization, with Pearson residuals to account for overdispersion. Ratios 


\section{TABLE 3 Difference-in-Difference Logistic Regression of Medication Adherence (PDC) of Members Enrolled in the MTM Program Versus Historical Comparators by Insurance Plan Type}

\begin{tabular}{|c|c|c|c|c|c|c|}
\hline \multirow[b]{2}{*}{ Insurance Plan Type } & \multicolumn{2}{|c|}{ MTM } & \multicolumn{2}{|c|}{ Historical Comparators } & \multirow[b]{2}{*}{ Odds Ratio ( $95 \% \mathrm{Cl}$ ) } & \multirow[b]{2}{*}{ P Value ${ }^{a}$} \\
\hline & Baseline & After Intervention & Baseline & After Intervention & & \\
\hline \multicolumn{7}{|l|}{ Medicare, \% } \\
\hline ACE/ARB & 71.2 & 69.4 & 69.4 & 69.5 & $0.92 \quad(0.69-1.21)$ & 0.531 \\
\hline Anticoagulant & 53.1 & 65.7 & 59.8 & 61.4 & $1.59 \quad(1.09-2.31)$ & 0.017 \\
\hline Cardiac & 78.8 & 81.8 & 77.7 & 79.4 & $1.09 \quad(0.84-1.43)$ & 0.511 \\
\hline Statin & 71.0 & 77.1 & 64.3 & 71.8 & $0.97 \quad(0.77-1.24)$ & 0.823 \\
\hline Diabetic & 74.3 & 76.6 & 75.6 & 75.4 & $1.15 \quad(0.81-1.62)$ & 0.435 \\
\hline Inhaler & 51.0 & 51.5 & 44.4 & 47.4 & $0.91 \quad(0.69-1.18)$ & 0.470 \\
\hline Antidepressants & 67.0 & 71.4 & 61.7 & 69.6 & $0.86 \quad(0.68-1.13)$ & 0.250 \\
\hline \multicolumn{7}{|l|}{ Medicaid, \% } \\
\hline ACE/ARB & 63.5 & 68.0 & 67.1 & 66.9 & $1.23 \quad(1.07-1.42)$ & 0.004 \\
\hline Anticoagulant & 45.4 & 55.9 & 51.4 & 55.0 & $1.32 \quad(1.05-1.67)$ & 0.019 \\
\hline Cardiac & 61.4 & 67.4 & 62.8 & 63.9 & $1.24 \quad(1.1-1.40)$ & 0.001 \\
\hline Statin & 58.1 & 65.8 & 62.1 & 65.7 & $1.19 \quad(1.04-1.37)$ & 0.015 \\
\hline Diabetic & 62.6 & 69.9 & 68.8 & 71.8 & $1.20 \quad(1.0-1.44)$ & 0.051 \\
\hline Inhaler & 36.7 & 41.1 & 36.3 & 40.3 & $1.02 \quad(0.88-1.19)$ & 0.798 \\
\hline Antidepressants & 64.1 & 63.7 & 68.7 & 64.5 & $1.19 \quad(1.08-1.31)$ & 0.001 \\
\hline \multicolumn{7}{|l|}{ Commercial, \% } \\
\hline ACE/ARB & 70.9 & 76.0 & 67.4 & 71.9 & $1.05 \quad(0.93-1.20)$ & 0.419 \\
\hline Anticoagulant & 48.4 & 56.8 & 53.1 & 59.2 & $1.10 \quad(0.85-1.39)$ & 0.458 \\
\hline Cardiac & 69.8 & 78.1 & 71.4 & 74.5 & $1.32 \quad(1.17-1.50)$ & $<0.001$ \\
\hline Statin & 63.4 & 71.9 & 61.8 & 64.5 & $1.28 \quad(1.15-1.44)$ & $<0.001$ \\
\hline Diabetic & 73.5 & 80.6 & 71.9 & 77.3 & $1.12 \quad(0.97-1.31)$ & 0.124 \\
\hline Inhaler & 42.0 & 46.2 & 36.2 & 40.0 & $1.01 \quad(0.86-1.19)$ & 0.900 \\
\hline Antidepressants & 65.2 & 69.3 & 66.2 & 68.3 & $1.10 \quad(0.96-1.25)$ & 0.155 \\
\hline
\end{tabular}

avalues in bold are statistically significant.

$A C E=$ angiotensin-converting enzyme; $A R B=$ angiotensin receptor blocker; $M T M=$ medication therapy management; $P D C=$ proportion of days covered.

of the means were compared using chi-square statistics. Generalized estimating equation for logistic regression was used to fit the model for medication adherence (defined as PDC per patient), and differences were compared using chisquare statistics. Mean difference was reported for cost and utilization, while odds ratio (OR) was reported for medication adherence. All costs were adjusted to 2017 U.S. dollars.

Subgroup analysis was performed for the following conditions based on having had an associated claim for the diagnosis of interest before enrolling in an MTM program: congestive heart failure, coronary artery disease, hypertension, dyslipidemia, diabetes mellitus, COPD, asthma, and depression. Additional subgroup analysis was performed for each insurance type (i.e., Medicare, Medicaid, and commercial) and for each intervention target.

Intervention targets included outreach to members with duplication of therapeutic classes, medications for which compliance is essential to disease control, medications that are at risk for abuse or overuse, medication considered high risk when prescribed to members aged over 65 years, prescribed medications with potential drug interactions, medications requiring regular laboratory monitoring, prescribed medications that may be contraindicated based on medical history, gaps in pharmaceutical therapy, and medications with a maximum daily dose (Table 1). 
All analyses were conducted using SAS version 9.4 (SAS Institute, Cary, NC). A P value of 0.05 was considered statistically significant.

\section{Results}

There were 20,264 members enrolled in the MTM program between January 2017 and June 2018. Of those members, 13,348 met the eligibility criteria for the study, and 10,747 were matched to a historical comparator (Figure 1). Members enrolled in the MTM program were more likely female (56.6\%) and had a mean (SD) age of 55.4 (15.0) years. Members had a high level of comorbidity, with $31.2 \%$ of members scoring $\geq 6.0$ on the age-adjusted Charlson Comorbidity Index. The most prevalent chronic conditions identified for these members were hypertension (77.4\%), hyperlipidemia (70.3\%), diabetes mellitus $(52.6 \%)$, coronary artery disease $(29.1 \%)$, COPD (22.7\%), asthma (21.7\%), congestive heart failure (14.3\%), and cancer (10.4\%). Over half of members $(60.3 \%)$ enrolled in MTM had been diagnosed with a behavioral health condition (Table 2).

Members enrolled in the MTM program tended to be younger with fewer comorbid conditions than those identified as historical comparators. This was primarily driven by the increased identification of members enrolled in the commercial and Medicaid plans. The medical per member per month (PMPM) was similar between the intervention and control groups, but the PMPM for pharmaceuticals was $\$ 186$ higher in the control group at baseline (data not shown).

Proportion of care activities undertaken in the intervention period compared with the control period were significantly different: "sent letter to physician" (67\% vs. $87 \%)$, "sent letter to member" (15\% vs. 0\%), "pharmacist phone call to physician" (15\% vs. $0.1 \%)$, and "pharmacist phone call to member" (13\% vs. $7 \%$ ). Compared with the control group, $26.6 \%$ vs. $16.8 \%$ of the intervention group had 2 care activities, and $8.54 \%$ versus $1.05 \%$ had at least 3 care activities.

\section{MEDICATION ADHERENCE}

Overall, medication adherence measured by PDC significantly improved for members enrolled in the MTM program who were prescribed anticoagulants $(\mathrm{n}=1,862 ; \mathrm{OR}=1.28,95 \%$ $\mathrm{CI}=1.09-1.48, \mathrm{P}=0.002)$; cardiac rate control medications $(\mathrm{n}=4,154 ; \mathrm{OR}=1.23,95 \% \mathrm{CI}=1.14-1.34, \mathrm{P}<0.001)$; statins $(\mathrm{n}=4,170$; $\mathrm{OR}=1.20,95 \% \mathrm{CI}=1.11-1.30, \mathrm{P}<0.001)$; diabetic medications $(\mathrm{n}=2,596 ; \mathrm{OR}=1.11,95 \% \mathrm{CI}=1.0-1.24, \mathrm{P}=0.050)$; and antidepressants ( $\mathrm{n}=4,270$; $\mathrm{OR}=1.14,95 \% \mathrm{CI}=1.06-1.23, \mathrm{P}=0.001$; Table 3). There were no significant differences observed for hypertensive medications $(\mathrm{N}=3,868 ; \mathrm{OR}=1.06,95 \% \mathrm{CI}=0.98-1.17$,
$\mathrm{P}=0.173)$ or asthma/COPD inhalers $(\mathrm{N}=2,069 ; \mathrm{OR}=0.97,95 \%$ $\mathrm{CI}=0.87-1.08, \mathrm{P}=0.574$; data not shown).

Within the different plan types, there were several significant differences observed in medication adherence (Table 3). Overall improvements in medication adherence were primarily driven by the Medicaid population, for which significant improvement was realized across all therapeutic classes tested except for inhaler adherence. The commercial population realized significant improvements in adherence for cardiac medications and statins, while the Medicare population only realized significant improvement in anticoagulant adherence.

\section{UTILIZATION}

Compared with the historical controls, there were reductions in unplanned visits (i.e., visits emanating from the emergency room where the patient is either discharged home, admitted for inpatient care, or admitted for observation at the hospital facility and then discharged home). These reductions occurred across all lines of business. For example, there was an $11 \%$ reduction in unplanned care $(12 \%$ in commercial, $10 \%$ in Medicaid, and $12 \%$ in Medicare) and an $8 \%$ reduction in emergency room visits $(10 \%$ in commercial, $9 \%$ in Medicaid, and 5\% in Medicare; results not shown).

\section{COST OF CARE}

A $\$ 130$ PMPM reduction in total cost of care was observed for members enrolled in MTM versus a reduction of $\$ 28$ PMPM for the historical comparators that was significant $(P<0.001$; Figure 2). This observed reduction was primarily driven by significantly decreased use of unplanned (unscheduled health care use) emergency, observation, and inpatient care. There was also a significant decrease in specialist, primary care provider, skilled nursing, and home care in members enrolled in MTM versus historical comparators (data not shown).

Pharmacy costs for members enrolled in MTM increased \$81 PMPM versus a \$61 increase in historical comparators $(P<0.001)$. Interestingly, while there was a significantly greater increase in pharmacy cost for commercial (difference-in-difference $=\$ 28 \mathrm{PMPM}, \mathrm{P}<0.001)$ and Medicaid (difference-in-difference $=\$ 21 \mathrm{PMPM}, \mathrm{P}=0.006)$, there was no significant difference in pharmacy costs observed for MTM members enrolled in Medicare (difference-in-difference $=-\$ 10$ PMPM, $P=0.234$ ). These results were expected, since medication adherence was also found to increase in these same populations, and may be an indicative of improved self-management in the commercial and Medicaid populations.

Significant decreases in total cost of care was primarily driven by reductions in medical cost and use because of 


\section{FIGURE 2 Change in Cost of Care (PMPM) 6 Months Before and After Intervention for MTM and Historical Comparators}

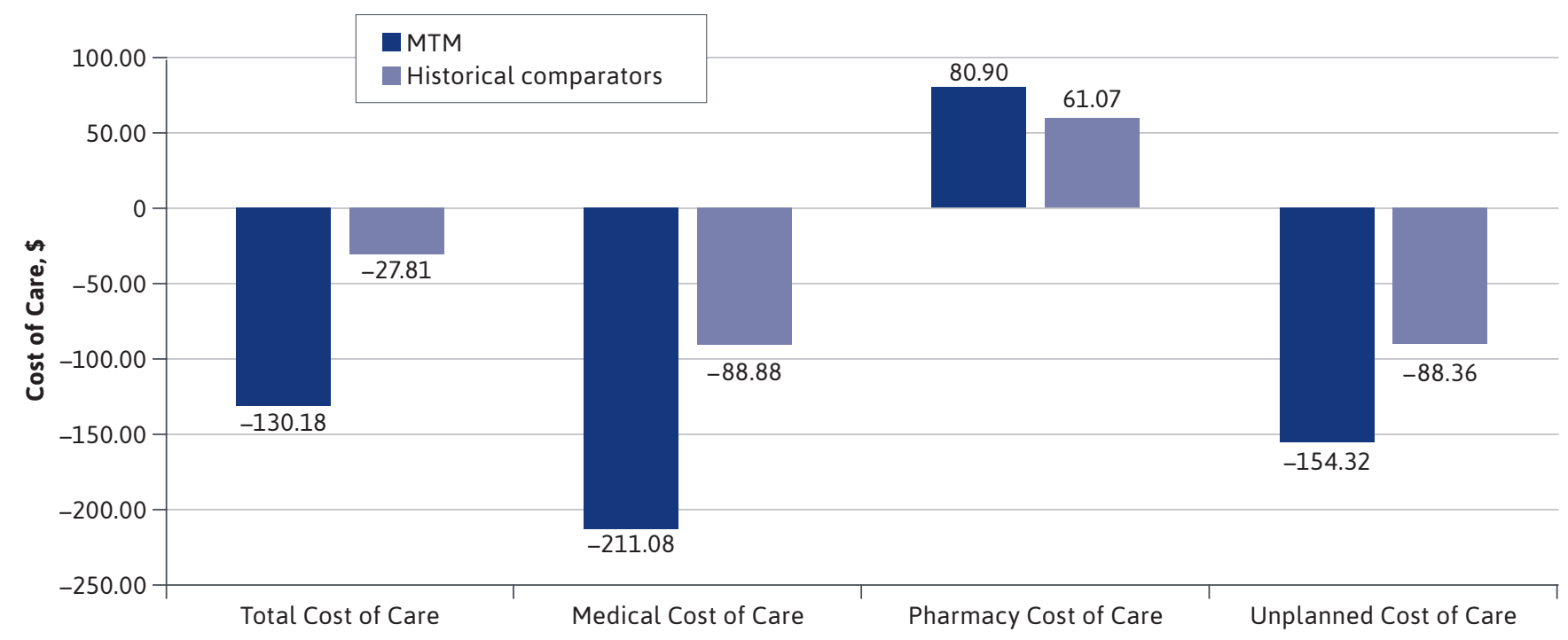

MTM = medication therapy management; $P M P M=$ per member per month .

enrollment in MTM. The following are the total PMPM reductions observed for members with congestive heart failure $(\$ 270, P=0.0055)$, coronary artery disease $(\$ 133$, $\mathrm{P}=0.0195)$, hypertension $(\$ 99, \mathrm{P}=0.0020)$, hyperlipidemia (\$103, $\mathrm{P}=0.0018)$, diabetes mellitus ( $\$ 141, \mathrm{P}=0.0004)$, COPD (\$125, $P=0.0257)$, and depression $(\$ 39, P=0.5919)$. There was no significant decrease observed for members with asthma enrolled in MTM.

After accounting for the cost to deliver the program (program implementation and maintenance cost such as attributable full-time equivalent case managers, pharmacists, and pharmacy interns), an ROI of $\$ 18.50$ (95\% $\mathrm{CI}=\$ 9.10-\$ 27.70)$ for every $\$ 1$ spent was observed, equating to $\$ 11$ million over 24 months.

\section{Discussion}

Our objective was to examine the effect of expanding eligibility and intensifying MTM services of an existing MTM program on cost of care, utilization of health care resources, and medication adherence. Our findings suggest that a more robust MTM program, achieved by expanding CMS MTM requirements to include non-Medicare beneficiaries, reduced the total cost of care overall and improved medication adherence in specific chronic conditions.
The ROI of \$18.50 for every \$1 spent is significantly higher than the $\$ 1.29$ from a comparable study by De Oliveira et al. (2010). ${ }^{2}$ That study evaluated an MTM program of another large integrated health system over a 10-year period (19982008). In both studies, pharmacists played a significant role and their program included Medicare, Medicaid, and commercial health plan members. In contrast, however, the De Oliveira et al. study used cost avoidance as a proxy for MTM savings, while we compared the total cost of care of our current MTM program with a propensity score-matched control group.

Most studies assessed face-to-face/in-person CMRs as part of their MTM service, but telephonic and telehealth formats are alternative delivery formats. ${ }^{1}$ A study comparing community pharmacists MTM services by telephone and by face-to-face formats found no significant differences in outcomes (identifying medication-related problems and providing education and medication reconciliation interventions). ${ }^{21} \mathrm{~A}$ review of the literature on telephonic delivery format on patient outcomes concluded that telephone format "may potentially reduce health care expenditures, hospitalizations, and mortality." UPMC implemented the MTM service using telephone calls to patients and providers and supplemented with mailed correspondence, and our findings confirm the benefit of using this delivery format. A review of the CMS summary of 2018 
MTM programs shows that almost all programs offered telephonic services, $89.6 \%$ offered face-to-face format, and $73.7 \%$ offered CMRs through telehealth technologies. ${ }^{4}$

The reduced PMPM in our study was driven mainly by reduction in unplanned care. This is consistent with the literature. For example, in another integrated health care system MTM study that compared MTM-eligible Medicare beneficiaries matched with Medicare beneficiaries who were not eligible for MTM services, there was a significant reduction in mortality and hospital admission but an increase in emergency room visits. The increase in emergency room visits from their study could be because their comparator group consisted of patients who were not eligible for MTM, but we used historical control group who were eligible for MTM. ${ }^{22}$

A prominent benefit of MTM in the literature is improvement in medication adherence. We found statistically significant improvements in PDC for patients taking anticoagulants, cardiac medications, statins, diabetic medications, and antidepressants but not for those taking hypertension medications or those using asthma/ COPD inhalers. It is encouraging to highlight that these improvements were driven mainly by Medicaid recipients in the cohort.

CMS Medicare star ratings requirements include reporting the medication adherence for specific chronic conditions, which likely influenced baseline medication adherence in this group. There is no such medication adherence requirement for Medicaid recipients, and knowing that they have a higher illness burden than privately insured enrollees, ${ }^{23}$ such improvements could have a significant effect on their quality of life.

CMS has been at the forefront of using incentives to promote quality of care through its value purchasing program. Having required MTM services for Medicare recipients and realizing the value to Medicare beneficiaries, CMS has been expanding the eligibility criteria periodically. In 2007, it initiated the 5-year Part D Enhanced Medication Therapy Management Model to study the effect of expanding eligibility for the MTM program. ${ }^{24}$ Under the enhanced MTM program, the 6 sponsors in the program have increased eligibility under the traditional MTM program from $7.9 \%$ in 2016 to $71.7 \%$ in 2017 . The expansion included varying the intensity of services provided, lowering the thresholds of the eligibility criteria (such as our study), and involving new partners in program provision, including call centers, community pharmacies, and outside partners (vendors). CMS recognizes that such an expansion will increase the program, so it is examining the effect of payment incentives on outcomes, including reduction in Medicare expenditures. ${ }^{24}$

The greatest effect of UPMC MTM intervention was on unplanned care among Medicaid and Medicare beneficiaries-2 groups of interest to public policy. MTM has been shown to improve health care quality and cost, and our study adds to the value of enhanced eligibility, increased pharmacist involvement, and use of telephone calls/mailings instead of face-to-face only delivery formats. Although there was an increase in pharmacy and program costs, the cost savings from reduction in unplanned care was greater, resulting in a positive ROI.

\section{LIMITATIONS}

This study has some limitations to consider. As an observational study based on administrative claims data, we do not claim causality. We increased robustness and improved study design with a propensity score-matched historical control, but it still is subject to biases from unobservable variables. In addition, we recognize that our findings are limited to similar integrated health care systems that have the capacity to examine the effect on pharmacy and medical claims and enhanced ability to coordinate with providers. Finally, we found success with our reproducible program; however, ability to adapt it to existing MTM programs in different health plans could present its own challenges.

\section{Conclusions}

Expanding MTM eligibility and intensifying MTM services reduced cost of unplanned care and increased pharmacy cost but reduced overall total cost of care, which resulted in a positive ROI.

\section{DISCLOSURES}

There was no funding for this project except employees' time. All authors are employees of UPMC and have no conflicts of interest to report.

\section{REFERENCES}

1. Dezeeuw EA, Coleman AM, Nahata MC. Impact of telephone comprehensive medication reviews on patient outcomes. Am J Manag Care. 2018;24(2):e54-e58.

2. De Oliveira DR, Brummel AR, Miller DB. Medication therapy management: 10 years of experience in a large integrated health care system. J Manag Care Pharm. 2010;16(3):185-95. doi: 10.18553/jmcp.2010. 16.3.185.

3. Shoemaker SJ, De Oliveira DR, Alves M, Ekstrand M. The medication experience: preliminary evidence of its value for patient education and counseling on chronic medications. Patient Education Couns. 2011;83(3):443-50. 
4. Centers for Medicare \& Medicaid Services. 2019 Medicare Part D medication therapy management (MTM) programs. Fact sheet. Summary of 2019 MTM programs. September 25, 2019. Accessed January 14, 2021. https://www. cms.gov/Medicare/Prescription-Drugcoverage/PrescriptionDrugCovContra/ Downloads/CY2019-MTM-Fact-Sheet.pdf

5. American Pharmacists Association, National Association of Chain Drug Stores Foundation. Medication therapy management in pharmacy practice: core elements of an MTM service model (version 2.0).

J Am Pharm Assoc (2003). 2008;48(3):341-53.

6. Troung HA, Groves N, Congdon HB, Dang DT, Botchway R, Thomas J. Potential cost savings of medication therapy management in safety-net clinics. J Am Pharm Assoc (2003). 2015;55(3);55(3):269-72.

7. Hirsch JD, Steers N, Adler DS, et al. Primary care-based, pharmacist-physician collaboration medication-therapy management of hypertension: a randomized, pragmatic trial. Clin Ther. 2014;36(9):1244-54.

8. Spinler SA, Cziraky MJ, Tang F. et al. Assessing Medicare beneficiary eligibility for medication therapy management programs naming PINNACLE, a natural cardiovascular data registry. Am Health Drug Benefits. 2013;6(7):367-74.

9. Wittayanukorn S, Westrick SC, Hansen RA, et al. Evaluation of medication therapy management services for patients with cardiovascular disease in a selfinsured employer health plan. J Manag Care Pharm. 2013;19(5):385-95.

doi: 10.18553/jmcp.2013.19.5.385

10. Hirsch JD, Gonzales M, Rosenquist A, Miller TA, Gilmer TP, Best BM.

Antiretroviral therapy adherence medication use, and health care costs during 3 years of a community pharmacy medication therapy management program for Medi-Cal beneficiaries with HIV/AIDs. J Manag Care Pharm. 2011;17(3):213-23. doi: 10.18553/jmcp.2011.17.3.213
11. Fox D, Reid LD, Klein GE, Myers W, Foli K. A medication therapy management program's impact on low-density lipoprotein cholesterol goal attainment in Medicare Part D patients with diabetes. J Am Pharm Assoc (2003). 2009;49(2):192-99.

12. Bunting BA. Smith BH, Sutherland SE. The Asheville Project: clinical and economic outcomes of a community-based long-term medication therapy management program for hypertension and dyslipidemia. J Am Pharm Assoc (2003). 2008;48(1):23-31.

13. Bunting BA, Cranor CW. The Asheville Project: long-term clinical, humanistic, and economic outcomes of a communitybased medication therapy management program for asthma. J Am Pharm Assoc (2003). 2006;46(2):133-47.

14. Barnett MJ, Frank J, Wehring H, et al. Analysis of pharmacist-provided medication therapy management (MTM) services in community pharmacies over 7 years. J Manag Care Pharm. 2009;15(1):18-31. doi: 10.18553/jmcp.2009.15.1.18

15. Isetts BJ, Brown LM, Schondelmeyer SW, Lenarz LA. Quality assessment of a collaborative approach for decreasing drug-related morbidity and achieving therapeutic goals. Arch Intern Med. 2003;163(15):1813-20.

16. Isetts BJ, Schondelmeyer SW, Heaton AH, et al. Effects of collaboration during therapy management on patient's perception of care and health-related quality of life. Res Social Adm Pharm. 2006;2(1):129-42.

17. Luder HR, Frede SM, Kirby SA, et al. TransitionRx: impact of community pharmacy post discharge medication therapy management. J Am Pharm Assoc (2003). 2015;55(3):246-54.

18. Moczygemba LR, Barner JC, Gabrillo ER. Outcomes of a Medicare Part D telephone medication therapy medication program. J Am Pharm Assoc (2003). 2012;52(6):e144-e52.
19. Touchette DR, Masica AL, Dolor RJ, et al. Safety-focused medication therapy management: a randomized controlled trial. J Am Pharm Assoc (2003). 2012;52(5):603-12.

20. Masica AL, Touchette DR, Dolor RJ, et al. Evaluation of a medication therapy management program in Medicare beneficiaries at high risk of adverse drug events: study methods. In: Henriksen K, Battles JB, Keyes MA, et al., eds. Advances in Patient Safety: New Directions and Alternative Approaches. Vol. 4: Technology and medication safety. Agency for Healthcare Research and Quality; 2008. Accessed January 14, 2021. https://www. ncbi.nlm.nih.gov/books/NBK43763/

21. Rivera J, Shcherbakova N, Vala C, Capoccia K. Community pharmacists' interventions and documentation during medication therapy management encounters delivered face-to-face versus via telephone: the devil is in the details. Res Social Adm Pharm. 2020;16(10):1447-51.

22. Hui RL, Yamada BD, Spence MM, Jeong EW, Chan J. Impact of a Medicare MTM program: evaluating clinical and economic outcomes. Am J Manag Care. 2014;20(2):e43-51.

23. Kaiser Family Foundation. Medicaid enrollees are sicker and more disabled than privately insured. March 14, 2013. Accessed January 14, 2021. https://www.kff.org/medicaid/slide/ medicaid-enrollees-are-sicker-and-moredisabled-than-the-privately-insured/

24. Centers for Medicare \& Medicaid Services. Part D enhanced medication therapy management (MTM) model. Accessed January 14, 2021. https:// innovation.cms.gov/innovation-models/ enhancedmtm 